\title{
PULP-CAPPING WITH MINERAL TRIOXIDE AGGREGATE
}

\author{
K. Peycheva \\ Conservative dentistry, FDM, MU - Sofia
}

Summary. There are two considerations for direct pulp capping - accidental mechanical pulp exposure and exposure caused by caries. Mineral trioxide aggregate (MTA) was used as pulp-capping material to preserve the vitality of the pulpal tissues. Follow-up examinations revealed that treatment was successful in preserving pulpal vitality and continued development of the tooth. On the basis of available information, it appears that MTA is the material of choice for some clinical applications. Material and methods: Cases $18-8$ teeth with grey MTA, 10 teeth with white MTA; diagnose: Pulpitis chronica ulcerosa, Electro pulpal test (EOD) - 30-35 $\mu \mathrm{A}$, pre-clinical X-ray - without changes in the structures, follow ups for 4 years. Successful treatments: without clinical symptoms and changes in the X-rays: 5 teeth with grey MTA, 8 teeth with white MTA for period of 4 years. Unsuccessful treatments: Clinical symptoms and sometimes changes in the X-ray: 3 with grey MTA, 2 with white MTA. MTA is an appropriate material for pulp-capping and follow-up examinations revealed that the treatment was successful in preserving pulpal vitality.

Key words: pulp-capping, mineral trioxide aggregate, pulpitis

\section{INTRODUCTION}

T hroughout the life of a tooth the pulp has a number of important functions. These include induction, formation, nutrition, defense and sensation. Following tooth development, the pulp retains its ability to form dentin [12]. Throughout the life of a tooth vital pulp tissue contributes to the production of secondary dentin, peritubular dentin (sclerosis) and reparative dentin in response to biologic and pathologic stimuli [34]. This enables the vital pulp to partially compensate for the loss of enamel or dentin caused by mechanical trauma or disease. How well it serves this function depends on many factors, but the potential for regeneration and repair is a reality in the pulp [12]. 
There are two considerations for direct pulp capping - accidental mechanical pulp exposure and exposure caused by caries. Major advances in the practice of vital pulp capping have been made, and the emphasis has shifted from the "doomed organ" concept to one of "hope and recovery". The exposed pulp possesses an inherent capacity for healing through cell reorganization and bridge formation when a proper biological seal is provided and maintained against leakage of oral contaminants [34]. Pulp capping is considered successful if the tooth remains vital and a bridge is formed within 75-90 days [28]. The major causes of post-operative inflammation and pulp necrosis are non-sterile procedures and bacterial micro-infiltration of the pulp via dentin tubules [35].

A vast number of materials and medicaments have been used as pulp-capping agents, i.e. gold and silver, different types of cements, antiseptic pastes, chemotherapeutics, ivory powder, dentin chips, plaster of Paris, magnesium oxide, calcium hydroxide, and many others [3, 4, 26, 27, 41]. One of the most promising materials consisted of spicules of dentin and pastes utilizing calcium hydroxide. The latter was introduced by Hermann in the 1920s (the original formula is still available today as Calxylf), which marked a new era in dental pulp therapy by demonstrating that a calcium hydroxide mixture induced bridging of the pulp surface with reparative dentin [34].

Recent attempts to develop kinder pulp capping materials have resulted in the development of two new materials, mineral trioxide aggregate (MTA) and Bioglass. MTA was initially developed to seal off all pathways of communication between the root canal system and the external surface of the tooth [19]. White MTA is a powder consisting of fine hydrophilic particles of tricalcium silicate, dicalcium silicate, tricalcium aluminate, calcium sulfate dehydrate and bismuth oxide. It also contains small amounts of other mineral oxides, which modify its chemical and physical properties. The powder consists of fine hydrophilic particles that set in the presence of moisture. Hydration of the powder results in a colloidal gel that solidifies to a hard structure. Bismuth oxide powder has been added to make the aggregate radiopaque. Since its first description in the literature by Lee et al. [19] in 1993, it has shown numerous exciting clinical applications in endodontics [1, $5,30,25,38,36,37]$. It was used on an experimental basis for several years with promising results, in both surgical and non-surgical applications, including rootend fillings, perforation repairs in roots or furcations, apexification, pulpotomies, and recently as a potential alternative material for pulp capping $[2,9,10,11,18]$. White ProRoot MTA was tested histologically in direct pulp capping procedures in subhuman primates (Pameijer $\mathrm{CH}$, unpublished data, 1999). Maintenance of vitality, a lack of inflammation and dentin bridge formation were the main characteristics of the findings. Although a promising material, little information is available on Bioglass [40] in pulp capping. 


\section{MATERIAL AND METHODS}

In that clinical study up to the number of the tooth and the cavity the cases were randomly chosen, but the diagnosis was general - Pulpitis chronica ulcerosa - 1st stage, appropriate for direct pulp-capping.

Cases 18 - 8 teeth with grey MTA, 10 teeth with white MTA; diagnose: Pulpitis chronica ulcerosa, Electro pulpal test (EOD) $-30-35 \mu \mathrm{A}$, pre-clinical X-ray - without changes in the structures.

Inclusion criteria: Ulcera up to $1 \mathrm{~mm}$, red blood, controlled bleeding up to $1 \mathrm{~min}$.

Control visits: EOD: 1 week, 1 month, 3rd month, 6th month, 1st, 2nd, and 3rd years;

Control X-rays: 1 st and 2nd year.

Rubber dam is used for all of the cases except the 2 cases of I class cavity of teeth 17 and 16.

\section{RESULTS}

1. Successful treatments: without clinical symptoms and changes in the X-rays 5 teeth with grey MTA for a period of 4 years: 16 (MO defect), 26 (MO defect), 17 (I class cavity), 25 (MOD cavity), 26 (MO cavity)

8 teeth with white MTA for a period of 4 years: 15 (MO defect), 22 (3 class cavity distolingual proxymolabial cavity), 15 (MO defect), 16 (I class cavity), 14 (MO cavity), Pulp. acuta purulenta 15 (MOD cavity), 14 MO cavity, 16 MO cavity

2. Unsuccessful treatments: Clinical symptoms and sometimes changes in the X-ray

3 with grey MTA: 1 with Per. acuta pululenta 17 (distooclusal cavity), 1 with Pulpitis acuta purulenta totalis 15 (MOD cavity), 1 with 37 (MO cavity),

2 with white MTA: 1 case - Per. chr. gr. diff. 15 (MOD cavity), Pulpitis acuta purulenta 17 ( 1 class cavity)
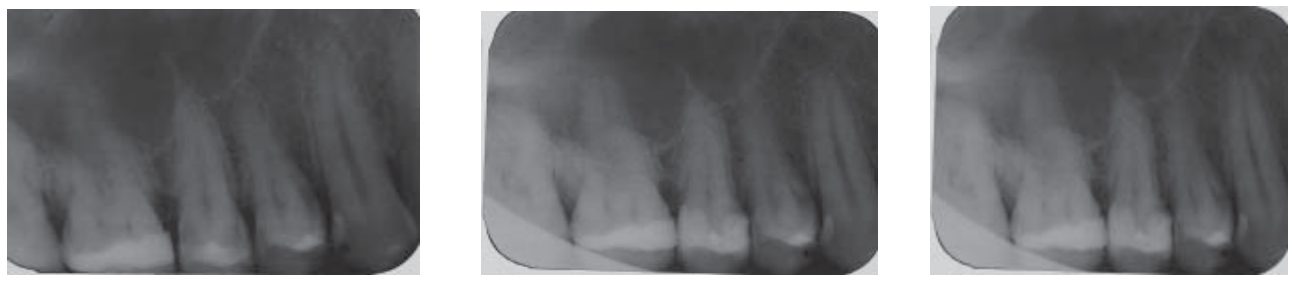

Fig. 1. Successful biological treatment with MTA

Intral X-Ray Tooth 25

1 year after treatment

4 yars after treatment 

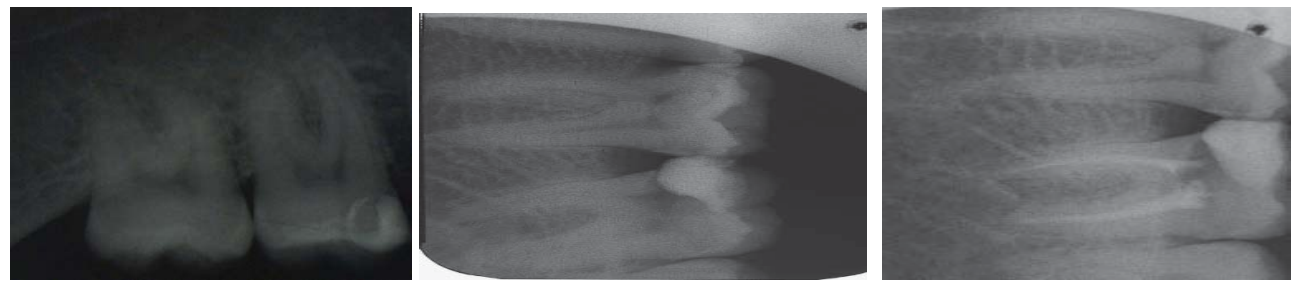

Fig. 2. Unsuccessful biological treatment with MTA

After treatment with grey

MTA tooth 37
1 year after treatment-

failure
After endodontic treatment

Table 1. Unsuccessful treatments

\begin{tabular}{|c|c|c|c|c|c|c|}
\hline & 1 week & $1^{\text {st }}$ month & $3^{\text {rd }}$ month & $6^{\text {th }}$ month & 1 year & 2 years \\
\hline Grey MTA & $\begin{array}{c}\text { "+ } \\
\text { Tooth } 17 ; \\
\text { DO }\end{array}$ & & $\begin{array}{c}\text { "+ " } \\
\text { Tooth } 15 \text { MOD }\end{array}$ & $\begin{array}{c}\text { Tooth } 37 \\
\text { MO }\end{array}$ & \\
\hline White MTA & $\begin{array}{c}\text { "+ } \\
\text { Tooth } 17 \\
\text { class }\end{array}$ & & & & $\begin{array}{c}\text { "+ " } \\
\text { Tooth 15 MOD }\end{array}$ \\
\hline
\end{tabular}

\section{DISCUSSION}

During the last 10-15 years, there has been a tremendous increase in our clinical "tools" (ie, materials, instruments, and medications) and knowledge from the trauma and tissue engineering fields that can be applied to regeneration of a functional pulp-dentin complex. Despite the progress made in the field of pulp biology, there is no single therapeutic regimen for direct pulp capping that can achieve, predictably and reliably, the goals of preserving tooth vitality and tooth function. What is agreed upon is that an effective pulp capping material should be biocompatible, provide a biological seal, prevent bacterial leakage and stimulate dentin bridge formation [18] Mineral trioxide aggregate showed clinical and radiographic success as a pulp capping agent in permanent teeth and was found to be as successful as calcium hydroxide when used for direct pulp capping in teeth. Further histological investigations are needed to support these findings [1, 13, 22, 39].

MTA has some known drawbacks such as a long setting time, high cost, and potential of discoloration. Hydroxyapatite crystals form over MTA when it comes in contact with tissue synthetic fluid. This can act as a nidus for the formation of calcified structures after the use of this material in endodontic treatments [20]. In the present study 2 cases with grey MTA have changed the color - grey color close to the obturation margins.

Usually less inflammation was observed with MTA. It should be emphasized that all previously quoted studies tested grey MTA $[2,9,10,11,28]$. White MTA is a 
promising new material that has been shown to be biocompatible and to seal pathways of communication between the root canal system and the external surface of the tooth [18]. To the best of the knowledge of the authors there is only one study to date that evaluated MTA as a direct pulp capping material [2]. White ProRoot MTA was as effective a pulp capping material as the control calcium hydroxide. Only a minimal association between clinical and histological findings for both materials was established. The study did not show significant differences in pulp vitality, superficial and deep inflammatory cell response, and presence of a dentin bridge between white MTA and calcium hydroxide [16].

A statistically significant difference was found in the diameter of exposure between white MTA $(x=0.35 \pm 0.19 \mathrm{~mm})$ and $\mathrm{CH}(x=0.25 \pm 0.09 \mathrm{~mm})$ groups. Larger exposures rather than smaller have a better chance to develop a bridge since in minute exposures the capping material may not be in contact with pulp tissues, which prevents odontoblastic regeneration [32]. Whether the difference in size is the reason white MTA performed better results than the grey MTA (although there was no statistically significant difference in performance) or material and/or techniquerelated issues determined the outcome, is difficult to draw conclusions given the relatively small sample size. Dentin bridge is the best solution for final healing and long-term success [16, 24, 29, 32].

Cox et al. [7] however, reported the presence of tunnel defects in dentin bridges after direct pulp - capping with various calcium hydroxide preparations and stated that these defects can act as pathways for microleakage causing inflammatory changes in the pulp. Stanley \& Pameijer [33] refuted this explanation and attributed tunnel defects to trauma of blood vessels caused by mechanical pulp exposure. The issue of tunnel defects remains an area of controversy, with publications by Murray et al. $[23,24]$ emphasizing the significance of their presence while Berk, [6] reported on the extensive use of calcium hydroxide in direct pulp capping and pulpotomies in humans with up to 53 years post-operative success, their significance to affect long-term success seems questionable. The exact mechanism by which MTA induces dentin bridge formation is not completely understood. Tziafas et al. [10] observed a homogenous zone of crystalline structures that was initially found along the pulp - MTA interface, while pulp cells showing changes in their cytological and functional state were arranged in close proximity to the crystals. Although MTA does not contain calcium hydroxide, calcium oxide is formed after hardening, which can react with tissue fluids producing calcium hydroxide $[8,16]$. Faraco et al. [10] likens the mechanism of MTA to calcium hydroxide. Koh et al. [15] demonstrated that MTA stimulates cytokine production in human osteoblasts and that the MTA calcium phosphate phase produces a change in cellular behavior, stimulating osteoblasts adhesion to the material. Koh et al. [18] believe hard tissue bridge deposition next to MTA occurs because of its sealing properties [17], biocompatibility, alkalinity and other properties associated with the material $[6,7$, $8,9,14,15,17,21,23,24,31,40]$. 


\section{CONCLUSIONS}

On the basis of available information, it appears that MTA is the material of choice for some clinical applications. MTA was used as pulp-capping material to preserve the vitality of the pulpal tissues. The study showed that MTA is an appropriate material for pulp-capping and follow-up examinations revealed that the treatment was successful in preserving pulpal vitality. More clinical studies are needed to confirm its efficacy compared with other materials.

\section{REFERENCES}

1. Abedi $\mathrm{H} ., \mathrm{J}$ Ingle. Mineral trioxide aggregate: A review of a new cement. - Calif Dent Assoc $\mathrm{J}$ 1995;23:36-39.

2. Agamy H., N. Bakry, M. Mounir, D. Avery. Comparison of mineral trioxide aggregate and formocresol as pulp-capping agents in pulpotomized primary teeth. - Pediatr Dent 2004;26:302-309.

3. Baker GR, Mitchell Df. Topical antibiotic treatment of infected dental pulps of monkeys. - J Dent Res 1969;48:351-355.

4. Barker B. Conservative treatment of cariously exposed vital pulps in posterior teeth with a glucocorticosteroid-antibiotic compound. - J Br Endod Soc 1975;8:5-15.

5. Bates C., D.Carnes, C. del Rio. Longitudinal sealing ability of mineral trioxide aggregate as a rootend filling material. - J Endod 1996;22:575-578.

6. Berk H. Save that tooth. Boston: Pulpdent Corporation, 2005: 140-150.

7. Cox CF, R. Subay, E. Ostro, S. Suzuki, Tunnel defects in dentin bridges: Their formation following direct pulp capping. - Oper Dent 1996;21:4-11.

8. Cvek M. A clinical report on partial pulpotomy and capping with calcium hydroxide in permanent incisors with complicated crown fracture. - J Endod 1978;4:232-237.

9. Eidelman E, G Holan, A Fuks. Mineral trioxide aggregate vs. Formocresol in pulpotomized primary molars: A preliminary report. - Pediatr Dent 2001;23:15-18.

10. Faraco I., R. Holland, Response of the pulp of dogs to capping with mineral trioxide aggregate or a calcium hydroxide cement. - Dent Traumatol 2001;17:163-166.

11. Fischer E, D.Arens, C. Miller, Bacterial leakage of mineral trioxide aggregate as compared with zincfree amalgam, intermediate restorative material, and Super-EBA as a root-end filling material. - J Endod 1998;24:176-179.

12. Fish E., Pathology of the dentin and dental pulp. - Br Dent J 1932; 53:351-363.

13. Ford Th, M. Torabinejad, H. Abedi, L. Bakland, Using Mineral Trioxide Aggregate as a Pupl- Capping Material. - The J. Am. Dent. Assoc.,Vol. 127, Issue 10, 1996, Pages 1491-1494.

14. Garfunkel A, Ulmansky M., Dental pulp pathosis: Clinicopathologic correlations based on 109 cases. - Oral Surg 1973;35:110-117.

15. Hasler J., D. Mitchel, Painless pulpitis. - J Am Dent Assoc 1970; 81:671-677.

16. Iwamoto C., E. Adachi, C. Pameijer, D. Barnes, et al, Clinical and histological evaluation of white ProRoot MTA in direct pulp capping. - American Journal of Dentistry, Vol. 19, № 2, April, 2006.

17. Jones MD, Gibb GH. Direct Pulp Capping with Dycal. - J Can Dent Assoc 1969;35:584-587.

18. Koh E., M.Torabinejad, P. Ford, K.Brady, Mineral trioxide aggregate stimulates A biological response in human osteoblasts. - J Biomed Mater Res 1997;37:432-439.

19. Lee S., M.Monsef, M. Torabinejad, The sealing ability of a mineral trioxide aggregate for repair of lateral root perforations. - J Endod 1993;19:541-544.

20. Masoud P., M. Torabinejad, Mineral Trioxide Aggregate: A Comprehensive Literature Review - Part III: Clinical Applications, Drawbacks, and Mechanism of Action. - J Endodontics, 36, (3), 2010, 400-413. 
21. Matsuo T, T. Nakanishi, H.Shimizu, S. Ebisu, A clinical study of direct pulp capping applied to carious-exposed pulps. - J Endod 1996;22:551-556.

22. Meligy El, A. Omar, David R., Comparison of Mineral Trioxide Aggregate and Calcium Hydroxide as Pulpotomy Agents in Young Permanent Teeth. - Pediatr. Dent., Vol. 28, Number 5, 2006, 399-404.

23. Murray P., A. Hafez, A. Smith, C. Cox, Hierarchy of pulp capping and repair activities responsible for dentin bridge formation. - Am J Dent 2002;15:236-243.

24. Murray P., A. Hafez, A. Smith, L. Windsor, Histomorphometric analysis of odontoblast-like cell numbers and dentine bridge secretory activity following pulp exposure. - Int Endod J 2003;36:106-116.

25. Nakata T, K. Bae, J. Baumgartner, Perforation repair comparing mineral trioxide aggregate and amalgam using an anaerobic bacterial leakage model. - J Endod 1998;24:184-186.

26. Negm M., E. Combe, A.Grant, Reaction of the exposed pulps to new cements containing calcium hydroxide. - Oral Surg Oral Med Oral Pathol O 1981;51:190-204.

27. Obersztyn A. Healing of pinpoint exposure of rat incisor pulp under various capping agents. $-J$ Dent Res 1966;45:1130-1143.

28. Pameijer C., H. Stanley, The disastrous effects of the "Total Etch" technique in vital pulp capping in primates. - Am J Dent 1998;11:S45-S54.

29. Parirokh M., M. Torabinejad, Mineral Trioxide Aggregate: A Comprehensive Literature review - Part III: Clinical Applications, Drawbacks, and Mechanism of Action, - J Endodontics, 36, № 3, 2010, 400-413.

30. Schwartz R., M. Mauger, D. Clement, W. Walker, Mineral trioxide aggregate: A new material for endodontics. - J Am Dent Assoc 1999;130:967-975.

31. Stanley H., A. Clark, C. Pameijer, N. Louw, Pulp capping with a Bioglass formula. - Am J Dent $2001 ; 14: 227-232$.

32. Stanley H., Criteria for standardizing and increasing credibility of direct pulp capping studies. - Am J Dent 1998;11:S17-S34.

33. Stanley H., Pameijer C., Guest editorial: Dentistry's friend, calcium hydroxide. - Oper Dent 1997;22:1-3.

34. Stanley H., Pulp capping: Conserving the dental pulp. Can it be done? Is it worth it? - Oral Surg Oral Med Oral Pathol. 1989;68:628-639.

35. Stockton L. Vital pulp capping: A worthwhile procedure. - J Can Dent Assoc 1999;65:328-331.

36. Torabinejad M, C. Hong, S. Lee, M. Monsef, P. Ford, Investigation of mineral trioxide aggregate for root-end filling in dogs. - J Endod, 1995;21:603-608.

37. Torabinejad M, P. Ford, McKendry D.H.Abedi, et al. Histologic assessment of mineral trioxide aggregate as a root-end Filling in Monkeys. - J Endod, 1997;23:225-228.

38. Torabinejad M., P. Smith, J. Kettering, P. Ford. Comparative investigation of marginal adaptation of mineral trioxide aggregate and other commonly used root-end filling materials. - J Endod, 1995;21:295-299.

39. Tuna D., A. Ölmez. Clinical long-term evaluation of MTA as a direct pulp capping material in primary teeth. Int. Endod. - J., 2008, 41, № 4, 273-278.

40. Tziafas D., O. Pantelidou, A. Alvanou, G. Belibasakis. The dentinogenic effect of mineral trioxide aggregate (MTA) in short-term capping experiments. - Int Endod J 2002;35:245-254.

41. Watts A., Paterson R. Simple metallic compounds as pulp-capping agents. - Oral Surg Oral Med Oral Pathol 1979;48:561-563.

\section{Corresponding author: \\ Kalina Peycheva \\ Department Conservativ Dentistry \\ Faculty of Dental Medicine \\ Medical University \\ 1 Sv. G. Sofiiski St. \\ BG - 1431 Sofia}

